\title{
INTERACTION OF METHANE WITH Ni(111) and Ni(100); DIFFUSION OF CARBON INTO NICKEL THROUGH THE (100) SURFACE; AN AES-LEED STUDY
}

\author{
F.C. SCHOUTEN, O.L.J. GIJZEMAN and G.A. BOOTSMA \\ Van 't Hoff Laboratory, University of Utrecht, Padualaan 8, Utrecht, The Netherlands
}

Received 5 March 1979; manuscript received in final form 16 May 1979

\begin{abstract}
The interaction of methane with $\mathrm{Ni}(100)$ results in the deposition of carbon in a carbidic form onto the surface. The sticking coefficient is initially $5 \times 10^{-9}$ and does not depend on temperature in the range $474-563 \mathrm{~K}$. This surface carbide consists of two different types with respect to their stability. A first kind may be made to diffuse into the bulk between 626-670 $\mathrm{K}$, similar to experiments on $\mathrm{Ni}(110)$. A second kind is more tightly bound and leads to a segregation type of behaviour. Methane does not interact with $\mathrm{Ni}(111)$.
\end{abstract}

\section{Introduction}

In a previous paper [1] we have presented the results of the interaction of methane with the $\mathrm{Ni}(110)$ surface. The purpose of the present study is to find out whether the interaction of methane is influenced by the atomic structure of the nickel surface. The decomposition of methane on nickel single crystal surfaces has received little attention, probably because methane has a very low reactivity. A reaction which can also lead to carbon deposition on the surface is the thermal decomposition of carbon monoxide [2-4], a gas which is always present in the background gas of a UHV-system. Tracy [2] observed CO decomposition on $\mathrm{Ni}(100)$ after a $\mathrm{CO}$ exposure of $10^{-5}$ Torr $\mathrm{s}$ at temperatures above $475 \mathrm{~K}$. Madden and Ertl [3] found carbon deposition on $\mathrm{Ni}(110)$ at $T=365 \mathrm{~K}$ and a $\mathrm{CO}$ exposure of $10^{-3}$ Torr s. Bertolini and Imelik [4] observed a complex LEED pattern which they ascribed to a surface carbide on $\mathrm{Ni}(111)$ after a $\mathrm{CO}$ exposure of $3.6 \times 10^{-4}$ Torr $\mathrm{s}$ at $413 \mathrm{~K}$. If the carbon content of the surface carbide is taken to be one monolayer, we calculate that the reactive sticking coefficient for the carbon monoxide decomposition on Ni(111) is of the order of $10^{-2}$. To avoid carbon build-up due to $\mathrm{CO}$, the $\mathrm{CO}$ partial pressure must be in the $10^{-11}$ Torr range.

Besides experiments on the decomposition of methane we have studied the diffusion of carbon from the (100) surface into the bulk. Experiments with carbon on the $\mathrm{Ni}(110)$ surface [5] and some models to describe the diffusion of foreign atoms from surfaces in to solids [6] have been previously reported. 


\section{Experimental}

\subsection{Materials}

The gases used, i.e. argon (purity $\geqslant 99.999$ vol\%), oxygen $(\geqslant 99.995 \%)$ and methane $(\geqslant 99.9995 \%)$, were purchased from Aga Gas B.V. Disc-shaped crystals (diameter $8 \mathrm{~mm}$, thickness $1 \mathrm{~mm}$ ) were spark-cut from $5 \mathrm{~N}$ nickel rods within $0.5^{\circ}$ of the (111) or (100) orientation. We checked the orientation before and after the sparkerosion process by taking von Laue back-reflection pictures. According to the manufacturer (Materials Research Corporation) the most important contaminants are: $\mathrm{C}(10.0 \mathrm{wt} \mathrm{ppm}), \mathrm{O}(<17.0 \mathrm{ppm}), \mathrm{S}(0.5 \mathrm{ppm})$ and $\mathrm{Cl}(1.0 \mathrm{ppm})$. The crystals were embedded in epoxy resin and mechanically polished with emery paper and diamond sprays with grain sizes as small as $0.25 \mu \mathrm{m}$. After this treatment the crystals were cleaned with distilled water in an ultrasonic bath and chemically polished for a few seconds with a mixture of 13 volume parts of concentrated acetic acid, 7 volume parts of concentrated nitric acid and 0.1 volume part of concentrated hydrochloric acid [7]. After this chemical polishing the crystals were rinsed as quickly as possible with water, removed from the resin and cleaned with distilled water and acetone p.a. in an ultrasonic bath. Finally the crystal was put in the UHV system described previously [1].

\subsection{Experimental procedure}

The vacuum chamber was baked out at $200^{\circ} \mathrm{C}$ for $\sim 48 \mathrm{~h}$. Thereafter the titanium wires of the sublimation unit were degassed. The sample was partially cleaned by argon ion bombardment and thereafter the sample and holder were heated to degas them. A sample temperature of $1070 \mathrm{~K}$ was reached. The surface of the crystal was cleaned down to the atomic level by the method already successfully applied to the $\mathrm{Ni}(110)$ surface $[1,5]$. For the (111) surface we succeeded in reducing the coverages of all contaminants below $\sim 0.005$ monolayer, as estimated from their AES sensitivities. On the (100) surface there remained a small but easily detectable amount of carbon ( $\sim 0.05$ monolayer). This amount segregated from the bulk of the crystal, since under good vacuum conditions no carbon was observed at the annealing temperature $(870 \mathrm{~K})$, but during cooling to the reaction temperature (474-536 K) the carbon AES signal developed (cf. fig. 1). No further attempts were made to clean the sample more thoroughly, because treatment with oxygen at temperatures significantly above room temperature can result in the dissolution of oxygen into the bulk. This oxygen might be removed by hydrogen treatment, but nevertheless the oxidation-reduction cycles might lead to an increased amount of contaminants dissolved in the bulk of the crystal. Therefore we took the Ni(100) surface, of which the AES spectrum is shown in fig. 1c, as the surface on which to start the decomposition of methane.

As has been shown previously [1] it was necessary to perform the adsorption 


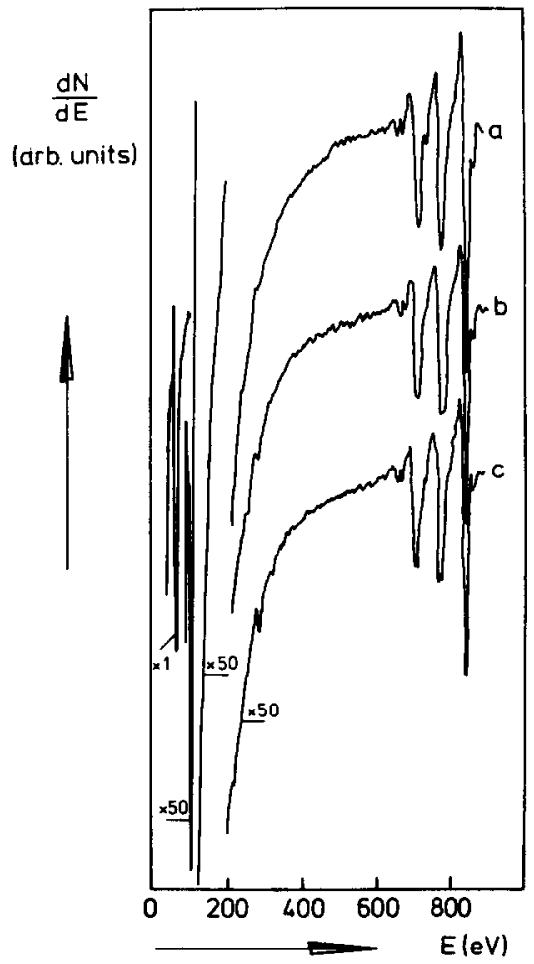

Fig. 1. Auger spectra of "clean" nickel surfaces: (a) Ni(111) surface; (b) Ni(100) surface at the annealing temperature $(870 \mathrm{~K})$; (c) $\mathrm{Ni}(100)$ surface after cooling to $503 \mathrm{~K}$. The peaks below $200 \mathrm{eV}$ are only shown for (b), but were practically identical for (a) and (c).

experiments without the use of pressure gauges and electron guns. The methane pressure in the UHV chamber was determined from the mTorr gauge readings in the gas handling system after equilibration with the chamber had taken place. After each exposure the UHV system was evacuated down to the $10^{-10}$ Torr range and the decomposition product on the surface was measured by AES. The retarding field type Auger spectrometer was adjusted as before [1]. The spectra were recorded in the $\mathrm{d} N / \mathrm{d} E$ versus $E$ mode and the carbon peak-to-peak height was considered to be proportional to the surface coverage. The LEED structures were obtained in the usual way, using the indirectly heated Ba-impregnated gun with the electron beam perpendicular to the surface.

\section{Results}

Reproducible results were obtained after baking the vacuum chamber not only after air admittance, but again after the degassing of the titanium wires, the crys- 
tal and the holder. The necessity of this second bakeout became especially apparent during the experiments on the (111) surface. In this section we first describe the experimental results on $\mathrm{Ni}(111)$ and then the results obtained for $\mathrm{Ni}(100)$.

\subsection{Methane interaction with $\mathrm{Ni}(11)$}

LEED pictures taken from the clean Ni(111) surface showed the expected pattern, whatever the position of the LEED beam on the surface. The first methane decomposition experiments were performed at $523 \mathrm{~K}$ and a methane pressure of $\sim 10^{-2}$ Torr. If the extra bakeout as described above was omitted irreproducible results were obtained for an identically prepared surface. For instance the reactive sticking coefficient varied over a factor of two. Also a Ni(111)-(16 $\sqrt{3} \times$ $16 \sqrt{3}) \mathrm{R}\left(30^{\circ}\right)$-C structure was observed. The same structure has been obtained after electron stimulated dehydrogenation of methane [8], thermal dehydrogenation of ethylene [9] and CO disproportionation [4,10]. The composition of the gas phase was determined by means of the quadrupole mass spectrometer. The upper limit of the $\mathrm{CO}$ pressure, the main interfering gas phase component, was found to be $10^{-9}$ Torr.

After an extra bakeout at $200^{\circ} \mathrm{C}$ for $24 \mathrm{~h}$ the experiments were repeated in the temperature range $523-618 \mathrm{~K}$ and a methane pressure of $10^{-2}$ Torr. Within the detection limit no carbon deposition was observed, even with exposure times as high as $5 \mathrm{~h}$. The partial $\mathrm{CO}$ pressure was below $10^{-10}$ Torr.

Methane exposures were also carried out at $573 \mathrm{~K}$ on Ni(111), which had been bombarded at room temperature for $30 \mathrm{~min}$ with $550 \mathrm{eV}$ argons ions at a current density as measured on the crystal of $\sim 3 \mu \mathrm{A} \mathrm{cm}^{-2}$. Again no carbon deposition was observed.

\subsection{Methane interaction with $\mathrm{Ni}(100)$}

The same stringent precautions with respect to the vacuum conditions were taken as during the final experiments on $\mathrm{Ni}(111)$. The decomposition of methane on the (100) surface was measured in the temperature range $474-563 \mathrm{~K}$ and mainly at a pressure of $10^{-2}$ Torr. In fig. 2 the kinetic curves as measured by AES are shown. The fine structure of the carbon KLL signal was in all cases of the carbide type. The curves at 503 and $563 \mathrm{~K}$ are the result of two runs over the entire exposure domain, while the other two curves are the result of three runs. At the higher temperatures ( 533 and $563 \mathrm{~K}$ ) the amount of carbon observed on the surface not only depends on the exposure but also on the elapsed time. If the number of experiments and consequently the total time spent at high $T$ is large, smaller values of $h_{\mathrm{C}} / h_{\mathrm{Ni}}$ are observed than after a few experiments up to the same exposure. This effect is the result of simultaneous diffusion of carbon into the bulk of the crystal, since if the surface is allowed to stand at 533 or $563 \mathrm{~K}$ for some time, the $h_{\mathrm{C}} / h_{\mathrm{Ni}}$ ratio decreases. This is shown by the vertical broken lines in fig. 2 . This effect was not observed at 503 and $474 \mathrm{~K}$. 
Two distinct observations can be made from the kinetic curves:

(i) The initial increase in the $h_{\mathrm{C}} / h_{\mathrm{Ni}}$ ratio does not depend much on the temperature of the crystal. The curves have, within experimental error, an identical slope.

(ii) At intermediate exposures there is a pronounced difference in slope between the curves.

Some experiments were performed to determine the influence of the methane pressure on the velocity of the process. These measurements were done at $10^{-3}$ Torr and $533 \mathrm{~K}$. Fig. 2 shows that at equal exposures almost the same $h_{\mathrm{C}} / h_{\mathrm{Ni}}$ values were observed. The systematic slight deviation from the points observed at $p=$ $10^{-2}$ Torr may be explained by the above mentioned diffusion process.

To check the influence of the background gas the crystal was kept at $563 \mathrm{~K}$ for $16 \mathrm{~h}$ without the chamber being pumped. Only a slight increase in the $h_{\mathrm{C}} / h_{\mathrm{Ni}}$ ratio $(0.01)$ was observed, much smaller than the increase $(0.8)$ obtained when the crystal was exposed to methane at a pressure of $10^{-2}$ Torr for the same period of time.

\subsection{Diffusion and segregation of carbon through Ni(100)}

The results of two typical diffusion experiments are shown in fig. 3. As can be seen the surface carbon coverage decreases to a virtually constant level of $h_{\mathrm{C}} / h_{\mathrm{Ni}} \simeq$ 0.7 with a rate that increases with temperature. The initial carbon saturation coverage after methane exposures at $563 \mathrm{~K}$ was $h_{\mathrm{C}} / h_{\mathrm{Ni}} \simeq 1.4$. This value is different from that quoted in fig. 2 due to a change in experimental geometry which affected the angle of incidence of the electron beam. Since at this saturation coverage the overlayer showed a clear $\mathrm{p} 4 \mathrm{~g}$ pattern which corresponds to a $\mathrm{C}: \mathrm{Ni}$ ratio of $1: 2$ $[14,15]$, a $h_{\mathrm{C}} / h_{\mathrm{Ni}}$ ratio of 1.4 indicates an absolute coverage of $1 / 2$. Lower values of $h_{\mathrm{C}} / h_{\mathrm{N} 1}$ were taken proportional to the surface coverage, i.e.

$\theta=(1 / 2.8) h_{\mathrm{C}} / h_{\mathrm{Ni}}=\left(10^{-15} / 1.61\right) C_{\mathrm{s}}$,

where $C_{\mathrm{s}}$ is the surface carbon coverage in atoms $/ \mathrm{cm}^{2}$. This procedure neglects electrons emitted from carbon below the surface, whose contribution will be small due to their short mean free path and the low subsurface concentration. The present calibration procedure differs from that employed earlier [1] for Ni(110) in the sense that it relies on experimentally determined surface coverages instead of indirect comparisons via ellipsometry and ionisation cross sections.

The experimental results at temperatures between 626 and $670 \mathrm{~K}$ could be described by a relation

$h_{\mathrm{C}} / h_{\mathrm{Ni}}=\left(h_{\mathrm{C}} / h_{\mathrm{Ni}}\right)_{t=0}-\beta \sqrt{ } t$,

which holds up to $h_{\mathrm{C}} / h_{\mathrm{Ni}}$ values of about 0.8 (see fig. 4). Values of these constants are given in table 1 , as well as some derived quantities. With exposures below a $h_{\mathrm{C}}$ $h_{\mathrm{Ni}}$ value of 0.7 no diffusion could be observed in this temperature range, although a very slow decrease of the constant value of 0.7 could always be observed in the diffusion experiments after some hours. An Arrhenius plot of $\ln \beta$ versus 1000/T 


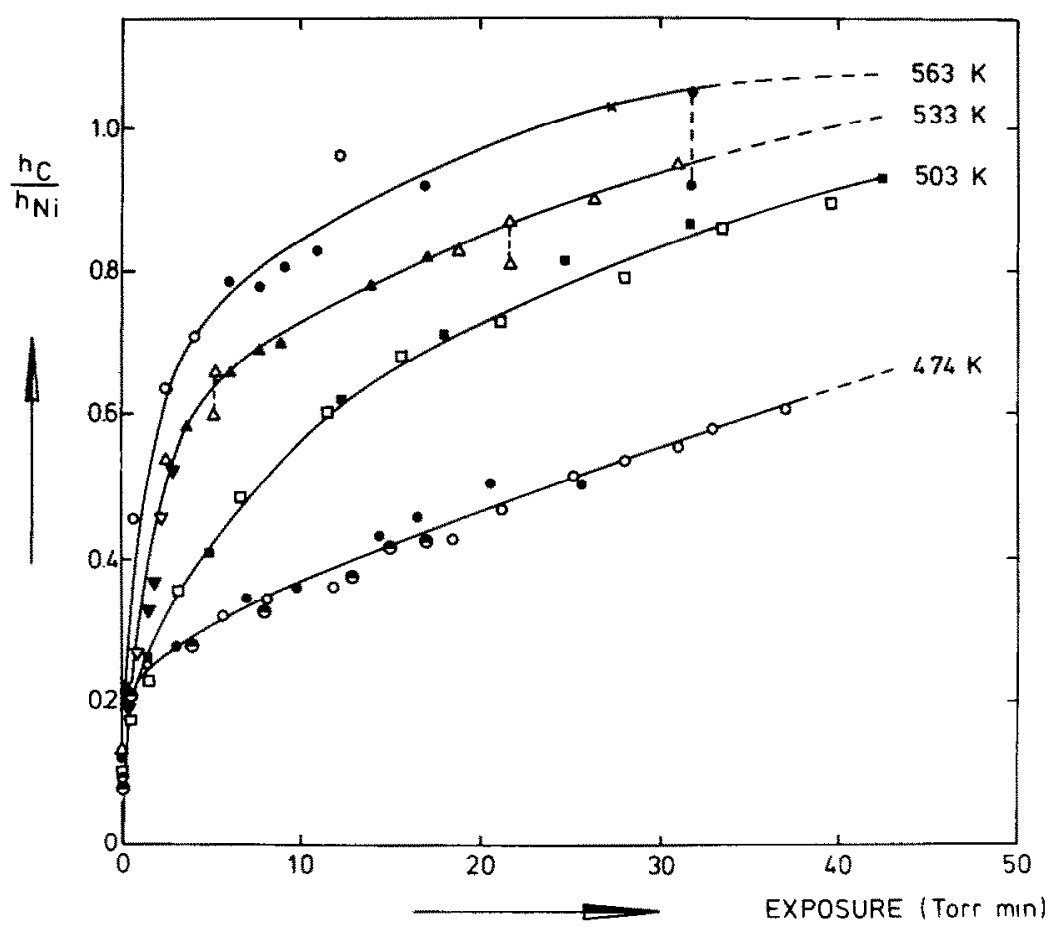

Fig. 2. Methane decomposition on $\mathrm{Ni}(100)$. Ratio of the carbon $272 \mathrm{eV}$ to the nickel $848 \mathrm{eV}$ peak as a function of exposure at different temperatures. Different runs at the same temperature are indicated with different symbols. Methane pressure $10^{-2}$ Torr, except for the measure* ments designated by the symbol $\mathrm{v}$ at $533 \mathrm{~K}$, which were obtained at $p=10^{-3}$ Torr. The dashed vertical lines indicate the effect of diffusion of carbon into the bulk if the surface is allowed to stand for some time at this high temperature.

Table 1

Comparison of calculated $C_{b}$ values with carbon solubilities extrapolated from data of ref. [21]

\begin{tabular}{|c|c|c|c|c|c|c|c|}
\hline \multirow[t]{2}{*}{$\begin{array}{l}T \\
(\mathrm{~K})\end{array}$} & \multirow[t]{2}{*}{$\begin{array}{l}\beta \\
\left(\min ^{-1 / 2}\right)\end{array}$} & \multirow[t]{2}{*}{$\begin{array}{l}10^{-14} \times C_{\mathrm{b} V} D \\
\left(\mathrm{~cm}^{2} \mathrm{~min}^{-1 / 2}\right)\end{array}$} & \multicolumn{2}{|c|}{$\begin{array}{l}10^{6} \times \sqrt{ } D \\
\left(\mathrm{~cm} \min ^{-1 / 2}\right)\end{array}$} & \multicolumn{2}{|c|}{$\begin{array}{l}10^{3} \times C_{\mathrm{b}} \\
(\mathrm{wt} \%)\end{array}$} & \multirow{2}{*}{$\begin{array}{l}10^{3} \times \\
\text { Solubility } \\
\text { (ref. [21]) }\end{array}$} \\
\hline & & & $\begin{array}{l}\text { (a) } \\
\text { Ref. [19] }\end{array}$ & $\begin{array}{l}\text { (b) } \\
\text { Ref. }[20]\end{array}$ & (a) & (b) & \\
\hline 626 & 0.054 & 0.28 & 2.90 & 0.137 & 2.1 & 0.49 & 3.1 \\
\hline 635 & 0.083 & 0.44 & 3.53 & 0.143 & 2.8 & 0.68 & 3.7 \\
\hline 645 & 0.098 & 0.50 & 4.35 & 0.163 & 2.6 & 0.69 & 4.1 \\
\hline 648 & 0.143 & 0.73 & 4.63 & 0.169 & 3.5 & 0.96 & 4.3 \\
\hline 663 & 0.145 & 0.74 & 6.26 & 0.203 & 2.6 & 0.81 & 5.1 \\
\hline 670 & 0.304 & 1.55 & 7.17 & 0.221 & 4.8 & 1.57 & 5.6 \\
\hline
\end{tabular}




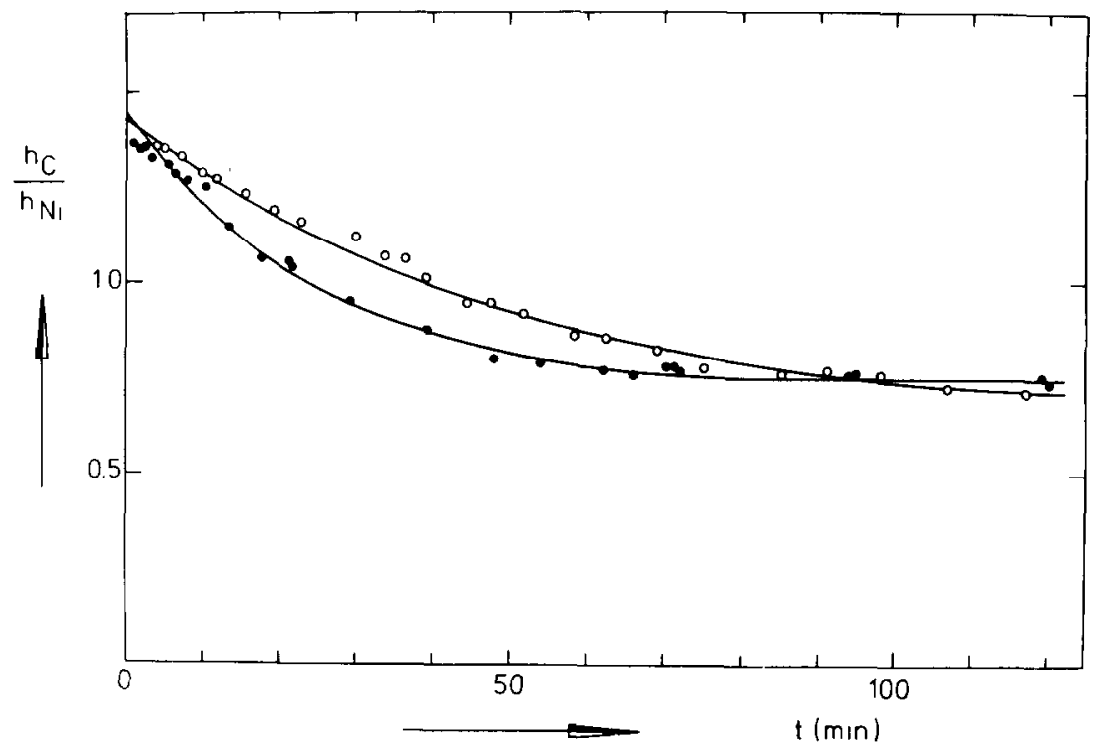

Fig. 3. Decrease of the relative carbon Auger peak with time for carbon on $\mathrm{Ni}(100):(\bullet) T=$ $645 \mathrm{~K} ;(0) T=635 \mathrm{~K}$.

yields, for $t$ given in minutes

$\ln \beta=(20 \pm 4)-(14 \pm 2) \times 10^{3} / T$,

which yields an activation energy of $28 \mathrm{kcal} / \mathrm{mole}$.

At temperatures above $700 \mathrm{~K}$ diffusion into the bulk became too rapid to be

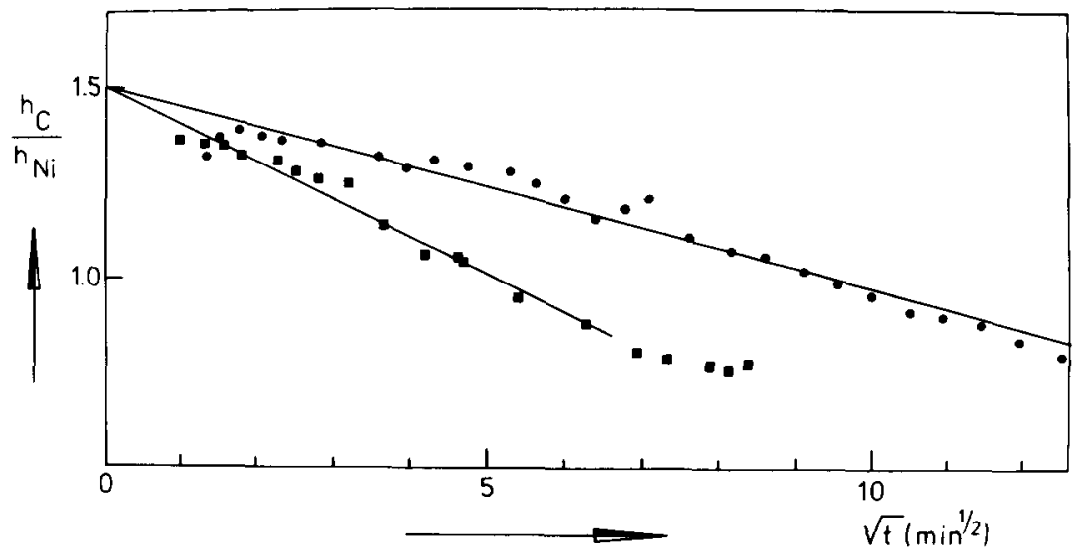

Fig. 4. Diffusion data of carbon into nickel (100) plotted according to eq. (1): $(\boldsymbol{\square}) T=645 \mathrm{~K}$; $(\bullet) T=626 \mathrm{~K}$. 


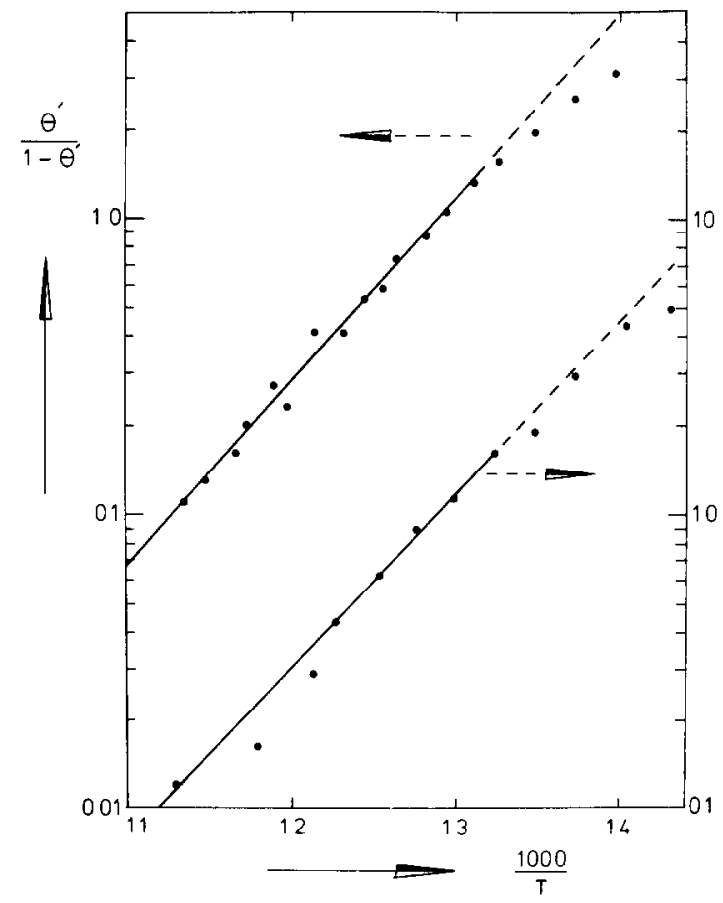

Fig. 5. Langmuir plot of $\theta^{\prime} /\left(1-\theta^{\prime}\right)$ versus $1 / T$ for two runs, each performed with increasing temperature after methane decomposition at $563 \mathrm{~K}$. The scales are displaced by one decade for clarity; $\theta^{\prime}$ is defined to be unity for a surface coverage of $\frac{1}{4}$ monolayer $\mathrm{C}$ on $\mathrm{Ni}(100)$.

analysed. Rather, a slowly decreasing surface coverage was obtained at each temperature, reminiscent of the (much slower) decreasing value of $h_{\mathrm{C}} / h_{\mathrm{Ni}} \simeq 0.7$ in the diffusion experiments. At temperatures above $770 \mathrm{~K}$ this surface coverage reached a steady value within a reasonable time $(\sim 2 \mathrm{~min})$ and was used to investigate segregation of carbon to the nickel $(100)$ face. In the temperature range $700-1000 \mathrm{~K}$ we define a surface coverage $\theta^{\prime}$ as equal to one if $h_{\mathrm{C}} / h_{\mathrm{Ni}}=0.70$, i.e. an absolute coverage of a quarter of a monolayer. The same convention has been adopted by Blakely and coworkers $[11,13,14]$. Fig. 5 shows a Langmuir plot of $\theta^{\prime} /\left(1-\theta^{\prime}\right)$ versus $1000 / T$ for two different runs. The lines obey the equation

$\ln \left[\theta^{\prime} /\left(1-\theta^{\prime}\right)\right]=-(18.5 \pm 0.9)+(14.4 \pm 0.8) \times 10^{3} / T$,

which implies a segregation enthalpy $\left(\Delta H_{\mathrm{seg}}\right)$ of $28.2 \mathrm{kcal} / \mathrm{mole}$. It should be remarked that this value applied only if the experiments were done - after cleaning and annealing the crystal - with increasing temperature. A lower value of $\Delta H_{\text {seg }}$ $(\sim 20 \mathrm{kcal} / \mathrm{mole})$ was obtained in a run with decreasing temperature and runs where carbon, segregated from the bulk after a previous experiment, was used on a nonannealed crystal. 
LEED photographs were taken during methane exposure at 533 and $563 \mathrm{~K}$. At $533 \mathrm{~K}$ up to $\theta=0.8 \theta_{\max }(=0.4 \mathrm{C} / \mathrm{Ni})$ the normal $1 \times 1$ pattern with an increase in background intensity was observed. Above this coverage the $\mathrm{Ni}(100)-\mathrm{p} 4 \mathrm{~g}$ $(2 \times 2)-\mathrm{C}$ structure developed. At $563 \mathrm{~K}$ the superstructure spots appeared at $\theta=$

$0.7 \theta_{\max }$ and had their brightest intensity, as judged visually, at saturation. During diffusion experiments at higher temperatures the reverse of the sequence described above occurred. The coverage of disappearance of the superstructure could be estimated to be about $0.7 \theta_{\max }$, although this figure is certainly not too reliable. The same superstructure has been found by other authors [12-14] and recently a model has been proposed with a carbon coverage of half a monolayer [15]. This value was used for the calibration of the carbon Auger signal.

\section{Discussion}

\subsection{Interaction of methane with Ni(111)}

The irreproducible carbon deposition observed on $\mathrm{Ni}(111)$ may be ascribed to $\mathrm{CO}$ disproportionation. About half a monolayer of carbon was formed on the surface in $200 \mathrm{~min}$. With a CO partial pressure of $10^{-9}$ Torr we obtain a reactive sticking coefficient for the $\mathrm{CO}$ disproportionation reaction of $\sim 0.1$. This value agrees reasonably well with the value of $\sim 0.01$ calculated from the literature data (section 1). From the results obtained after the second bakeout and the detection limit for carbon $(\sim 0.005$ monolayer) we obtain as upper limit for the reactive sticking coefficient of methane on $\mathrm{Ni}(111): s \leqslant 10^{-10}$.

Fast diffusion of carbon into the bulk, which might also explain the low reactive sticking coefficient, is excluded at the low temperatures of the experiment (523$618 \mathrm{~K}$ ). Moreover, carbon deposited from $\mathrm{CO}$ was readily observed on the surface. With a value of $10^{-2}$ for the sticking coefficient of the CO disproportionation reaction we calculate that the $\mathrm{CO}$ partial pressure has been lower than $10^{-10}$ Torr, as was found experimentally.

Argon ion bombardment did not enhance the reactivity, so either the defects introduced at room temperature are removed at the reaction temperature $(573 \mathrm{~K})$, or they are not reactive towards methane.

\subsection{Interaction of methane with $\mathrm{Ni}(100)$, the fate of carbon on $\mathrm{Ni}(100)$}

The data obtained at 533 and $563 \mathrm{~K}$ are influenced by the diffusion of carbon from the surface into the bulk (fig. 2). The curves obtained at 474 and $503 \mathrm{~K}$ did not show this effect. Therefore conclusions about the interaction of methane with the $\mathrm{Ni}(100)$ surface will be based mainly on these curves. At $474 \mathrm{~K}$ the reaction is relatively fast at the beginning and becomes slow at $h_{\mathrm{C}} / h_{\mathrm{Ni}} \approx 0.2$. The same type of curve has been obtained by Wright, Ashmore and Kemball [16] in their study of 
the dissociative adsorption of methane on nickel and iron films. However, the initial slope at different temperatures is the same, within experimental error, whereas Wright et al. found an increase in the slope with increasing temperature $\left(E_{\text {act }} \approx\right.$ $10 \mathrm{kcal} / \mathrm{mole}$ ). This difference can probably be explained if we consider the temperature of the gas. In our experiments the gas phase was at room temperature, while in the measurements of Wright et al. the gas and the surface were at the same temperature. Recently, Stewart and Ehrlich [17] observed that the dissociative chemisorption of methane on rhodium is enhanced by thermal activation of the methane gas; this observation supports the above-mentioned suggestion.

Above $h_{\mathrm{C}} / h_{\mathrm{Ni}} \approx 0.2$ the slope of the kinetic curves increases with increasing surface temperature. In this region further reaction of adsorbed carbon to a state different from that in which it is initially adsorbed is probably rate-determining. Dehydrogenation of adsorbed hydrocarbon radicals, which are fully accommodated to the surface temperature, might be one other possible explanation. However, electron bombardment of these radicals should enhance this process [18], whereas we found that if the chamber had been evacuated the Auger electron beam had no influence on the reaction.

The disappearance of carbon in to the bulk from the (100) face proceeds at a rate roughly equal to the corresponding process from the (110) face [5]. In the latter case bulk diffusion was shown to be rate limiting and could account for the total removal of surface carbon. However, as is seen in fig. 3 , on the (100) face the surface carbon is only partially removed via diffusion. It thus seems reasonable to invoke the existence of two different types of adsorbed carbon. One kind ( $\beta$ ) may be made to disappear in the temperature range 626 to $670 \mathrm{~K}$ (and probably at somewhat lower temperature too, cf. the discussion on the methane adsorption at $533 \mathrm{~K})$, the second kind $(\gamma)$ is more stable and tightly bound, and corresponds to $\mathrm{C}:$ Ni ratio of less than $1: 4$.

The diffusion of the $\beta$ carbon into the bulk can be described by the same model as used previously, viz. diffusion from a constant plane source, just underneath the surface. This model leads to $[5,6]$

$C_{\mathrm{s}}(t)=C_{\mathrm{s}}(0)-(2 / \sqrt{ } \pi) C_{\mathrm{b}} \sqrt{ } D \sqrt{ } t$,

where $C_{\mathrm{s}}(t)$ is the observed carbon surface coverage at time $t, C_{\mathrm{b}}$ the constant plane source bulk concentration (the driving force for diffusion) and $D$ the bulk diffusion coefficient. Comparing eqs. (4) and (1) and using the calibration factor relating $C_{\mathrm{s}}$ to $h_{\mathrm{C}} / h_{\mathrm{Ni}}$, we obtain $\beta=(2 / \sqrt{ } \pi) C_{\mathrm{b}} \sqrt{ } D \times(2.8 / 1.61) \times 10^{-15}$. Using the reported diffusion coefficients from Shovensin et al. [19] and Massaro and Petersen [20], we obtain values for $C_{\mathrm{b}}$ as given in table 1 . As previously [5], they compare well with solubility data of graphite in nickel. The temperature dependence of $C_{\mathrm{b}}$ is given by that of $C_{\mathrm{b}} \sqrt{ } D$ (or $\beta$ in eq. (2)) minus one half of the activation energy of $D$. This activation energy of $C_{\mathrm{b}}$ might be called a segregation enthalpy since by hypothesis $[5,6]$ it relates the equilibrium concentration of carbon in nickel to that of carbon in a surface carbide. Using the values for $D$ quoted previously we obtain 11 or 18 
$\mathrm{kcal} / \mathrm{mole}$ respectively. For this crystal face the value of $D$ reported by Shovensin gives a segregation energy $(11 \mathrm{kcal} / \mathrm{mole})$ which is close to the heat of solution of graphite in nickel $(\sim 10 \mathrm{kcal} / \mathrm{mole})$. The reverse situation occurs with the $(110)$ face where Massaro and Petersen's diffusion coefficient produced this agreement [5]. In view of the arguments presented previously [5] we have a slight preference for the diffusion data given by Shovensin.

The $\gamma$ carbon obeys a segregation type behaviour above $700 \mathrm{~K}$, similar to that reported by Blakely and coworkers $[11,13,14]$. However, our results differ from those of Blakely et al. in that no graphite was ever found on the surfacc. Also, our segregation enthalpy for the $\gamma$ carbon $(28 \mathrm{kcal} / \mathrm{mole})$ is higher than the reported value of $10 \mathrm{kcal} / \mathrm{mole}$. This is presumably due to the difference in doping levels of the crystals used or to their history. The free energy of segregation can contain a bulk concentration dependence if the bulk carbon behaves non-ideally. Depending on the assumptions about non-ideality different equations may be derived that lead to an increase in $\Delta H_{\text {seg }}$ with decreasing bulk concentration. Physically, these models mean that excess carbon is more stable when incorporated into an initially non-distorted bulk (i.e. at low bulk doping levels) than after incorporation into an already strained lattice. The same hypothesis applies when the cause of the different $\Delta H_{\text {seg }}$ values is ascribed to the history of the crystal. In our normal experiments carbon was deposited (from methane) on a clean and annealed crystal at $563 \mathrm{~K}$ and a diffusion and segregation run were carried out with increasing temperature. In this case carbon diffuses into a non-distorted nickel crystal. Upon lowering the temperature the defects produced by the interstitial carbon atoms are frozen in and a second run (with increasing $T$ ) requires carbon to diffuse into a strained crystal, leading to a lower value of $\Delta H_{\text {seg }}$ in agreement with our experiments.

The arguments presented above may seem to violate the idea that thermodynamic quantities are only defined in equilibrium systems. However, one may consider a nickel crystal, strained either through dissolved carbon or unannealed defects to be in (metastable) equilibrium. Thus we consider a strained nickel crystal "stable", although certainly less so than a perfectly annealed crystal. It is therefore not surprising that these two crystals will have different thermodynamic properties, e.g. a segregation enthalpy for carbon as can be deduced from our experiments.

\section{Conclusions and comparison with $\mathrm{Ni}(110)$}

(1) The sticking coefficients of $\mathrm{CH}_{4}$ on different low index $\mathrm{Ni}$ crystal faces differ (table 2). In view of the low sticking coefficient one might wonder whether differences in defect concentrations on the planes are responsible for the observed behaviour. However, the results with methane on Ar bombarded Ni(111) argue against this,

(2) Carbon deposition from $\mathrm{CH}_{4}$ proceeds via activated island growth on $\mathrm{Ni}(110)$, is initially temperature independent on $\mathrm{Ni}(100)$ and does not occur on $\mathrm{Ni}(111)$. 
Table 2

Summary of results for methane decomposition on nickel single crystals

\begin{tabular}{lclc}
\hline & $(110)$ & $(100)$ & $(111)$ \\
\hline Sticking coefficient $s$ & $10^{-8}$ & $5 \times 10^{-9}$ & $\leqslant 10^{-10}$ \\
Activation energy of $s(\mathrm{kcal} /$ mole $)$ & 21 & 0 & - \\
Maximum coverage $\mathrm{C}: \mathrm{Ni}$ & 0.7, & 0.5 & 0 \\
Surface carbide stable below & $610 \mathrm{~K}$ & $600 \mathrm{~K}$ & $\mathrm{a}, 1000 \mathrm{~K}$ \\
LEED pattern at maximum coverage & $4 \times 5$ & $\mathrm{p} 4 \mathrm{~g}$ & - \\
\hline
\end{tabular}

a $\beta$ Nickel carbide.

$b_{\gamma}$ Nickel carbide.

(3) Diffusion of carbon from a surface carbide into the bulk is diffusion limited on $\mathrm{Ni}(110)$ and $\mathrm{Ni}(100)$.

(4) Two types of surface carbide are present on $\mathrm{Ni}(100)$, an ordered $\beta$ phase (LEED structure $\mathrm{p} 4 \mathrm{~g}$ ) and a disordered $\gamma$ phase. This last compound appears more stable than the $\beta$ carbide or the carbide formed on $\mathrm{Ni}(110)$ surfaces.

\section{References}

[1] F.C. Schouten, E.W. Kaleveld and G.A. Bootsma, Surface Sci. 63 (1977) 460.

[2] J.C. Tracy, J. Chem. Phys. 56 (1972) 2736.

[3] H.H. Madden and G. Ertl, Surface Sci. 35 (1973) 211.

[4] J.C. Bertolini and B. Imelik, Ned. Tijdschr. Vacuum-Tech. 16 (1978) 24.

[5] F.C. Schouten, E. le Brake, O.L.J. Gijzenlan and G.A. Boutsma, Surface Sci. 74 (1978) 1.

[6] F.C. Schouten, O.L.J. Gijzeman and G.A. Bootsma, Ned. Tijdschr. Vacuum-Tech. 15 (1977) 46.

[7] W.J. McG. Tegart, The Electrolytic and Chemical Polishing of Metals, 2nd ed. (Pergamon, New York, 1959) ch. 10.

[8] G. Maire, J.R. Anderson and B.B. Johnson, Proc. Roy. Soc. (London) A320 (1970) 227.

[9] J.C. Bertolini and G. Dalmai-Imelik, in: Colloq. Intern. sur la Structure et Propriétés des Surfaces des Solides, Paris, 1969, p. 135.

[10] T. Edmonds and R.C. Pitkethly, Surface Sci. 15 (1969) 137.

[11] J.M. Blakely, CRC Crit. Rev. Solid State Sci. 7 (1978) 333.

[12] G. Dalmai-Imelik and J.C. Bertolini, Compt. Rend. (Paris) C270 (1970) 1079.

[13] L.C. Isett and J.M. Blakely, Surface Sci. 47 (1975) 645.

[14] L.C. Isett and J.M. Blakely, Surface Sci. 58 (1976) 397.

[15] J.H. Onuferko and D.P. Woodruff, Ned. Tijdschr. Vacuum-Tech. 16 (1978) 312.

[16] P.C. Wright, P.G. Asmore and C. Kemball, Trans. Faraday Soc. 54 (1958) 1692.

[17] C.N. Stewart and G. Fhrlich, J. Chem. Phys. 62 (1975) 4672.

[18] H.F. Winters, J. Chem. Phys. 63 (1975) 3462.

[19] A.B. Shovensin, A.H. Minkevitch and G.B. Scherbinski, Izv. Vysshikh Uchebn. Zavedenii, Chernaya Met. 1 (1965) 95.

[20] T.A. Massaro and E.E. Petersen, J. Appl. Phys. 42 (1971) 5534.

[21] K. Natesan and T.S. Kassner, Met. Trans. 4 (1973) 2557. 